\title{
LNG to Power in the Romanian port of Constanta
}

\author{
Vasile Rata ${ }^{1}$, Alin Hobjila ${ }^{1, *}$, and Liliana Rusu $^{1}$ \\ ${ }^{1}$ Department of Mechanical Engineering, 'Dunarea de Jos' University of Galati, 47 Domneasca St., 800008 Galati, Romania
}

\begin{abstract}
Nowadays, the raising of the global living standard are chan ging the lifestyle of each individual, which also leads to increased consumption of goods and services. The factors mentioned, directly affect shipping and cru ising activities. These two types of activities are classified as major pollutant makers within ports, near urban residences, caused by the combustion of fuel in large auxiliary engines to provide the power needed to operate the systems specific to the two types of ships. In this context, our objective is to find solutions such as the one presented in this study. They have emerged as a scenario for the sizing of an onshore or a floating power plant using Liquefied Gas Natural (LNG) for the port of Constanta in Romania, which is considered to be the largest port of the European Union in the Black Sea.
\end{abstract}

\section{Introduction}

Pollution, in our days, is one of the main problems in the world and is the reason for damaging sea life and air, which affects human health indirectly. It is well known that human activities are having an important role in the changes in atmospheric composition that affect global climate changes [1]. In these conditions, the European Union (EU) has an active role in cutting its greenhouse gas (GHG) emissions, the target is $20 \%$ cut until 2020 compared with 1990 [2]. The preventing measures together with innovative solutions can be the key solutions to reach this target.

The European Maritime Safety Agency (EMSA) has an important role in supporting this effort, providing especially technical assistance in relation to $\mathrm{GHG}$ emissions from ships [3]. Also, EMSA ensures support to the Member States in implementing the MRV (Monitoring, Reporting, Verification) regulation that is applied from July 2015. In the last International Maritime Organization (IMO) report is mentioned that annually the maritime transport is responsible for around $2.5 \%$ of global GHG emissions [4], and the trend is to increase from $50 \%$ to $250 \%$ by 2050 . This increase will be directly related to the future economic developments

Therefore, it is very important to find more innovative and constructive ideas to reduce pollution, so we can find a balance between human's activities and environment. As we have seen in recent years, if this balance does not exist, strange and dangerous phenomena can occur even in the area where it does not normally happen. As above mentioned, the naval industry is one of the main sources of global pollution, and therefore it is very important to reduce the consumption of maritime energy, even when they are stationed in harbors.

Many countries around the world are concerned with the protection of the environment and Romania is one of them. This study is focused on the port of Constanta, but can be applied to most of the ports from the world. Since Constanta is the most important port of the European Union in the Black Sea region, the trend is to strengthen its market share and to grow with small steps, but it is sure that as it will become more crowded, the level of pollution will grow in the near future.

\section{The target area}

Port of Constanta is the most important of the European Union in the Black Sea region (see Table 1, data processed from [5]). It is located near Constanta, in Romania, on the western shore of the Black Sea. Constanta harbour is located in the proximity of the two key points of Black Sea, the Bosporus Strait and the two waterways to the centre of Europe through the Danube River, by the Sulina Branch and the Danube-Black Sea Canal.

Table 1. 2012 Black Sea's ports ranking, by total traffic.

\begin{tabular}{|c|c|}
\hline Rank no. & Name of Port \\
\hline 1 & Novorossiysk \\
\hline 2 & Constanta \\
\hline 3 & Yuzhny \\
\hline 4 & Odessa \\
\hline 5 & Tuapse \\
\hline 6 & Taman \\
\hline 7 & Ilyichevsk \\
\hline 8 & Mariupol \\
\hline 9 & Rostov on Don \\
\hline 10 & Varna \\
\hline 11 & Batumi \\
\hline
\end{tabular}

\footnotetext{
* Corresponding author: hobjila.alin.daniel@gmail.com
} 
Another factor that strategically positions the Romanian Black Sea port is that it is halfway between the Odessa port of Ukraine and the Bosporus Strait, which causes an increase in the number of ships in transit. The maritime route measures almost 370 nautical miles (Figure 1). Figure 1 represent one of the most important maritime routes in the Black Sea, it is processed in [6] and there were used data description from [7].

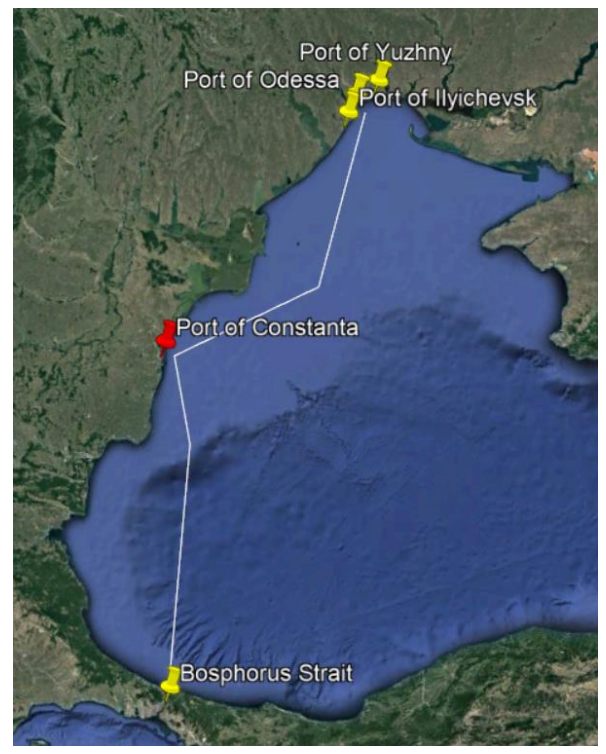

Fig. 1. Constanta harbour on the route between Bosporus and Odessa harbour

All these positive remarks have led to economic growth in the region, which is positive, come with a number of negative points that need to be addressed with interest from the beginning in order to mitigate fewer desirable effects of this industrial development.

\subsection{The regional context of the imminent increase in the harbor's activity}

South-East Europe is forced to develop its large infrastructure by building, expanding, rehabilitating modern road, rail and river networks. Romania has a plan to develop infrastructure from these points of view, of regional interest at the standards of the European Union, which in the next 5-10 years will lead to a sharp increase in the volume of goods that could reach the Constanta harbour on the sea routes. This is also supported by strategic objectives to create connections to northern and central Europe on water, road or rail.

The socio-economic context of the Eastern European region is in a continuous metamorphosis, leading to major changes in relatively short time periods in countries such as Romania and its neighbours, with examples like Bulgaria, Moldova, Serbia, Hungary and Ukraine, will help them reach over the next 10-20 years, from developing countries to developed countries, Figure 2.

Taking into account these perspectives and the fact that this regional economic and social context will lead to higher demand for products, due to a better standard of living for the countries mentioned above, an immediate strategy is needed to further develop the intermodal node, represented as the most important port of the European Union at the Black Sea.

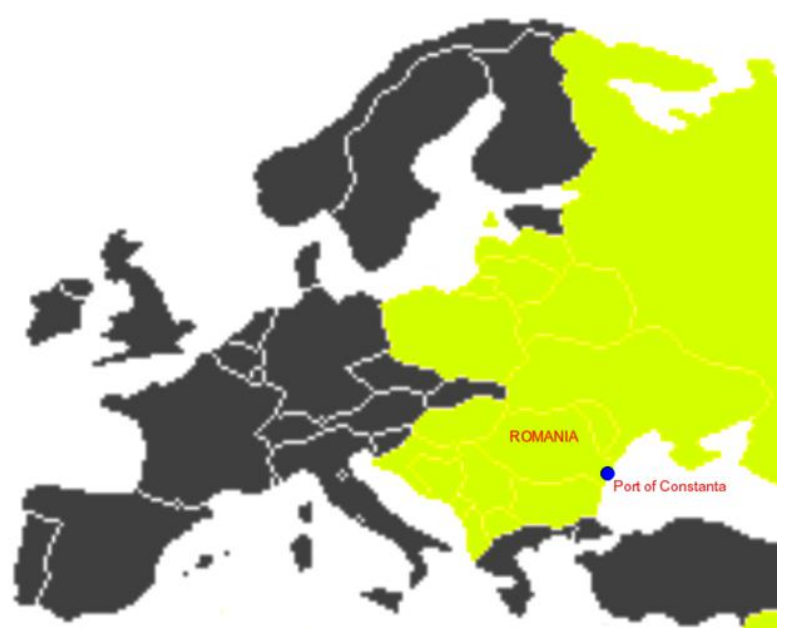

Fig. 2. Map of developing EU countries (yellow) [8]

At the same time, this context leads to an increase in the size and the number of the ships that will dock in Constanta harbour. However, real questions arise about the age of ships using port services caused by the general trend of aging of the fleet of vessels operating in the Black Sea's geographical area [9].

The facilities offered by Constanta harbour consist in the fact that:

- It is an important hub in the European container shipping network.

- Provides modern facilities for passengerships.

- It is an important center for cereals in the central and South-Eastern region of Europe.

- It is capable of intermodal connection: railway, road infrastructure, river, aerial and through pipelines.

The Danube river connection provides added value to Constanta port, also obvious from the last years statics, where it can be seen that the number of river ships calling for port services is almost double than the number of maritime ships (see Table 2, data processed from [10]).

Table 2. Constanta harbour ship calls.

\begin{tabular}{|c|c|c|c|c|}
\hline Ship calls/Year & $\mathbf{2 0 1 4}$ & $\mathbf{2 0 1 5}$ & $\mathbf{2 0 1 6}$ & $\mathbf{2 0 1 7}$ \\
\hline M aritime calls & 4,771 & 4,605 & 4,331 & 4,093 \\
\hline River calls & 10,053 & 9,765 & 10,203 & 9,272 \\
\hline Total calls & 14,824 & 14,370 & 14,534 & 13,365 \\
\hline
\end{tabular}

These features are due to the fact that the Constanta Port through the Danube-Black Sea Canal ensures the transit of cargos to Central Europe in a cheaper way for 
large volumes, which avoids congestion on the road traffic and is even more efficient than the rail.

The field of large energy consumption maritime ships is represented by cruise ships and container vessels for the transport of refrigerated containers, which also has to assure in a fairly high quantity of energy when stationery in ports.

The most important pollution factors regarding the maritime activity in Constanta harbor are caused by the emissions that these ships produce when they are anchored in port and the fact that Constanta port is in the proximity of the inhabited areas of more than 300000 residents (Figure 3).
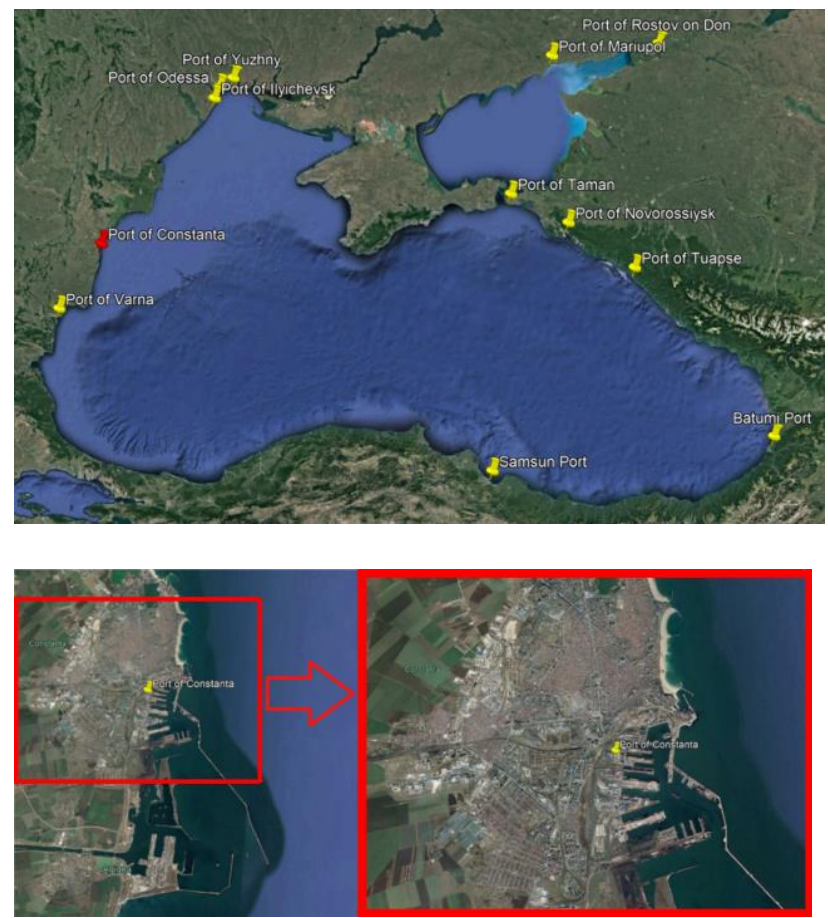

Fig. 3. Satellite view of harbor and the city Constanta [6]

An expected trend, even if it recent history of Constanta port does not show this fact, (Figure 4), it is the imminent increase in the demand for docking of cruise ships at the Romanian Black Sea coast. Although the tendency shown in Figure 4 is a decrease from the peak of 2016, with about 100 cru ise ships that have been registered in the roadstead, the data presented in Figure 5 (data processed from [11]) launches the premises of new prospects for this branch of touris $m$ due to the number of these types of ships that are under construction or just ordered in the coming years.

\subsection{Scenarios considered}

A number of more than 130 cruise ships are known to be in a very advanced stage to enroll in the next 8 years. Furthermore, it is possible that the trend does not decrease so suddenly, as the data is continuously updated and the tendency may remain constant, resulting in even 200 or even more in reality at the end of the 8 years. We can think of two scenarios regarding the migration of the cruise ship fleet in the Black Sea.
In the Scenario 1 is considered that the new ships found in the order book are not intended to navigate the Black Sea basin, so tour operators will try to maximize their profits by introducing new routes with ships from older generations whose place will be occupied by new ships built after 2018, in the geographic area of Black Sea to keep revenue at a higher rate.

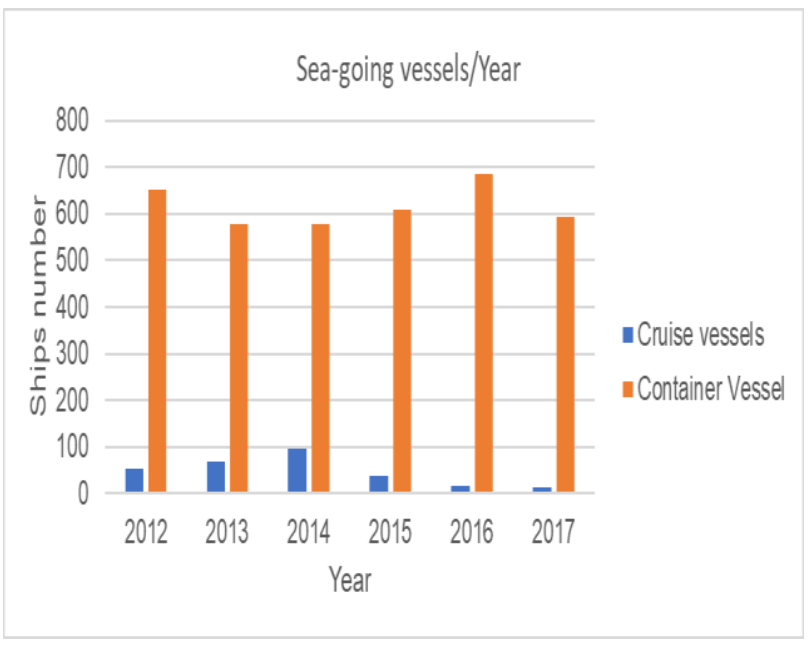

Fig. 4. Sea-going container and cruise vessels per year [10]

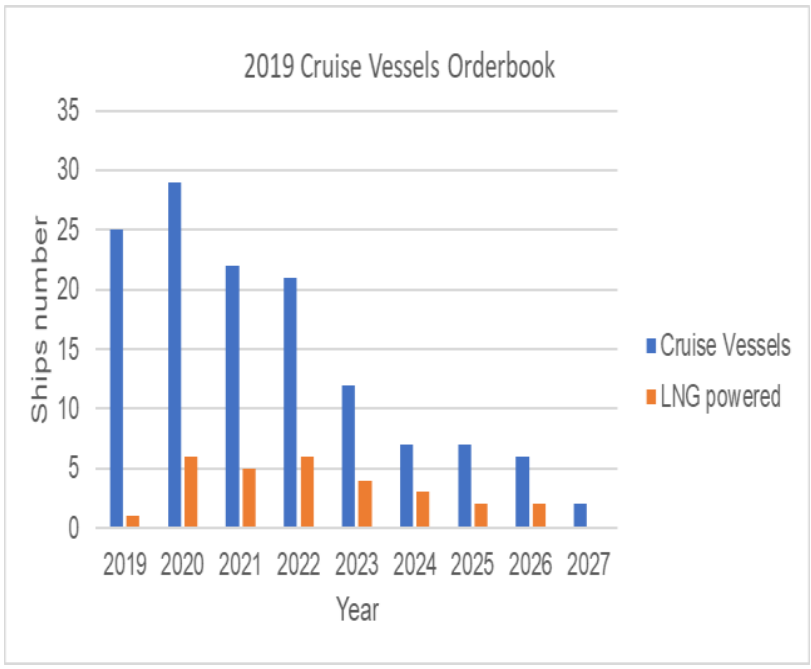

Fig. 5. Cruise Vessels orderbook 2019

The direction that will be chosen by the most cruise ship operators will be the option of introducing new routes into the Black Sea basin, to the detriment of the idea in Scenario 2. Because ships were built decades ago, even though they have been upgraded for countless times, cannot mask the aging and are prone to higher risks. For these reasons, they will be withdrawn into new zones, relative "exotic", because they have been forgotten in recent years or have gone out of the tourist objective for countless reasons. Here, however, it can keep a decent price because of the rather low offer compared to the potential demand for growth.

Scenario 2 considers that new ships are built to raise new standards in the field of cruise services, increasing competition and offering much more attractive packages to the general public for famous and consecrated 
destinations and routes through much more cheaper prices than the present time using ships from older generations.

By comparison, they will lose revenue if they choose to use similar routes with newer or much better-rated ships due to the natural laws of competition.

\section{Results}

In order to size an LNG power plant for Constanta Port, it is necessary to estimate the energy requirement; for this purpose, data from the specialty literature will be used to describe the potential consumers.

A rough analysis asserts that a ship docks during a year about 100 days in port and that in average it burns 5 cubic meters of marine fuel to carry out daily harbour activities, resulting in between 1 and $4 \mathrm{MW}$ used for a container ship port and between 5 and $10 \mathrm{MW}$ for a cruise ship. This statement is supported by the data presented in Figure 6 (data processed from [12]) and also, by the values inform Table 3 (data processed from [13]) if it is taken into account, as usual, it is in use about $70 \%$ of the power installed on board. As example, if 4 diesel generators are installed, only 3 in optimal usage will be used, in the conditions of an optimal load of power consumption.

For a second validation it was created a dummy ship using with the main characteristics of six different cruise vessels, which are scheduled to arrive in the next period of time in Port of Constanta, by averaging the values were obtained that most ships have an average age of 35 years, an average power output of $16 \mathrm{MW}$ and an auxiliary power system of $13.5 \mathrm{MW}$.

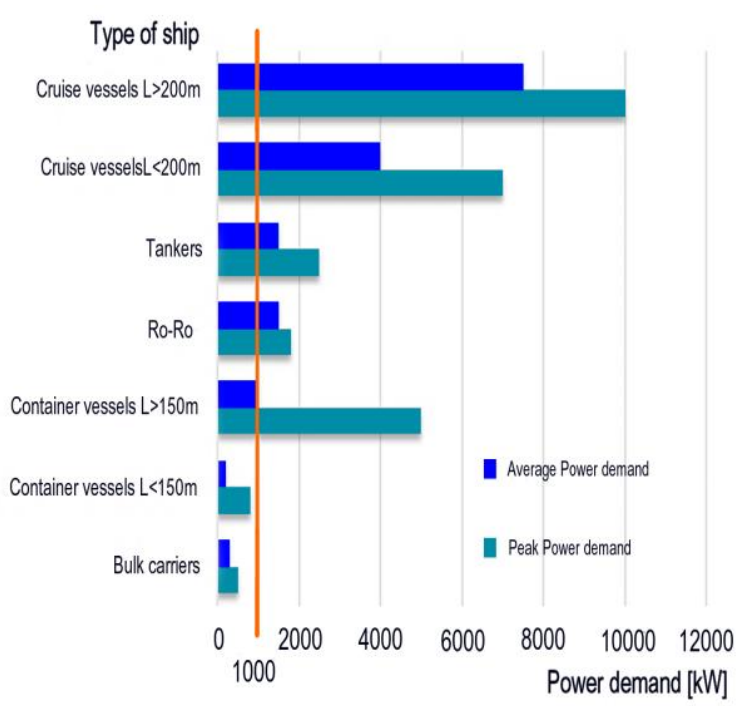

Fig. 6. Power demand $[\mathrm{kW}]$ by type of ship.

In the Table 3 are selected a series of ships that have scheduled the retreats in the following period with a stop in Constanta Port, so they can make a description of the typology of ships that will benefit from the port facilities.

According to annual vessel statistics of the Port Container type, the average is about 2 per day [14], but considering that a ship is stationed for container loading and unloading operations for an average of two days it results that 4 ships are found daily in port, for container handling operations.

Table 3. Scheduled Vessels in Constanta 2019-2022.

\begin{tabular}{|c|c|c|}
\hline $\begin{array}{c}\text { Name of ships/Main } \\
\text { characteristics }\end{array}$ & $\begin{array}{c}\text { Gen Set } \\
(\mathbf{k W})\end{array}$ & Year of built \\
\hline mv Aegean Odyssey & 1800 & 1973 \\
\hline Albatros & 7346 & 1973 \\
\hline ms Prinsendam & 21120 & 1988 \\
\hline Azamara Journey & 18600 & 2000 \\
\hline Boudicca & 7346 & 1973 \\
\hline $\begin{array}{c}\text { Crystal Symphony } \\
\text { Average Ships } \\
\text { characteristics }\end{array}$ & $\mathbf{1 3 5 7 8}$ & $>\mathbf{3 5}$ years old \\
\hline
\end{tabular}

Hence, resulting important values and taken into account the gas emitted by the combustion of the generators of these ships, an example is being given in Table 4 (data processed from [15]), which represents a mediation for 6 empirical measurements made at the ship in docking conditions.

Table 4. The quantity of noxes results from measurements.

\begin{tabular}{|c|c|c|c|c|}
\hline $\begin{array}{c}\text { Pel } \\
(\mathbf{k W})\end{array}$ & $\begin{array}{c}\text { Nox } \\
(\mathbf{K g} / \mathbf{h})\end{array}$ & $\begin{array}{c}\mathbf{S O x} \\
\mathbf{( K g} / \mathbf{h})\end{array}$ & $\begin{array}{c}\mathbf{C O} \\
(\mathbf{K g} / \mathbf{h})\end{array}$ & $\begin{array}{c}\mathbf{C O 2} \\
\mathbf{( K g} / \mathbf{h})\end{array}$ \\
\hline 1000 & 14.1 & 6.7 & 1.2 & 794.3 \\
\hline
\end{tabular}

It will be considered two cruise ships of more than 150 meters long, such as ships in Table 3 whose average length tends to $200 \mathrm{~m}$, the average power requirement not taking into account the peak points, would be $20 \mathrm{MW}$. In order to be able to withstand the maximum required levels for the proper functioning of the ships, a power plant of $30 \mathrm{MW}$ can be recommended.

\section{Conclusions}

It turns out that an approach is needed regarding the evolution of port facility requirements for a period of 10 to 50 years, in relation to new environmental protection requirements, by reducing emissions of greenhouse gases and gases produced in a major percentage of freight, cruise ships and more. Such a project can be a big opportunity as it can be funded by European funds, due to the context of the entire port state and shipping sectorat the macroeconomic level.

It is advisable to follow examples of good harbor practices in the areas affected by the installation of very restrictive regulations called Emission Control Areas (ECAs) such as those in the Baltic Sea and the North Sea [16]. 
The location of the Constanta Port in the immed iate vicinity of the city raises serious concerns about the health of the citizens from the perspective of the air quality in this area in the long run.

As an upcoming direction of study, an economic analysis must be carried out to determine what type of LNG plant is feasible to be built in Port of Constanta, because from the point of view of efficiency, numerous calculations show that there are no differences between an onshore LNG and a floating power plant [17]. Also, from this economic study can be established if is selected a small $20 \mathrm{MW} \mathrm{LNG}$ power plant, a medium of $30 \mathrm{MW}$ one or a large $40 \mathrm{MW}$ size.

A realistic scenario for a $40 \mathrm{MW}$ LNG plant can be launched in the context where ports are required at European level to facilitate the supply of LNG fuel, so the port infrastructure and the initial project can be provided with such a station of electricity production, which can introduce the excess in the national network in the new context in which Romania started to constantly import energy.

\section{Acknowledgment}

This work was carried out in the framework of the project ACCWA (Assessment of the Climate Change effects on the WAve conditions in the Black Sea). sunported bv Ministrv of Research and Innovation, CNCS-UEFISCDI, grant number PN-III-P4-ID-PCE-2016-0028, within PNCDI III.

\section{References}

1. TR, Karl, K.E. Trenberth, Modern global climate change, Science 302(5651), 1719-1723 (2003)

2. EU climate action (accessed January 2019) https://ec.europa.eu/clima/citizens/eu en

3. EMSA (accessed January 2019) http://emsa.europa.eu/main/airpollution/greenhouse-gases.html

4. IMO, Third IMO. Greenhouse Gas Study, Executive Summary and Final Report, London, (2014)
http://www.imo.org/en/OurWork/Environment/Pollu tionPrevention/AirPollution/Pages/Default.aspx

5. Black Sea Container Ports, Drewry Maritime Advisors, The European Sea Ports Conference ESPO (2013) https://www.espo.be/media/300520130830-vanaale.pdf (accessed January 2019)

6. Google Earth application

7. V. Rata, C. Gasparotti, L. Rusu, The Importance of the Reduction of Air Pollution in the Black Sea Basin, Journal of Mechanical Testing and Diagnosis, 2, 5-15 (2017)

8. en.wikipedia.org/wiki/Developing_country (accessed January 2019)

9. V. Raţă, L. Rusu, Assessing the traffic risk along the main Black Sea maritime routes, International Conference on Traffic and Transport Engineering, 4, 290 (2018)

10. Annual Report 2017 Port of Constanta, (2018) portofconstantza.ro (accessed January 2019)

11. cruis eindustrynews.com/cruise-news/cruise-shiporderbook.html (accessed January 2019)

12. D. Tarnapowicz, S. German-Galkin, International standardization in the design of "shore to ship" power supply systems of ships in port, Management Systems in Production Engineering, 26(1), 9-13 (2018) DOI 10.2478/mspe-2018-0001

13. cruisemapper.com (accessed January 2019)

14. Master Plan al Portului Constanta, (2014) portofconstantza.ro (accessed January 2019)

15. T. Borkowsky, D. Tarnapowicz, JK, Shore to ship" system - an alternative electric power supply in port, Powertrain and transport, 19, 49 (2012)

16. Options for establishing shore power for cruise ships in port of Copenahgen Northavon, City \& Port Development, CMP and the City of Copenhagen (2015)

17. R. I. Chowdhury, P. Saha, M. Rahman, M. A. Hannan, Feasibility Study of Hybrid Floating Power Plant Concept at the Bay of Bengal 6th International Youth Conference on Energy (IYCE), (2017) 